OPEN ACCESS

Edited by:

Michael Holinstat,

Thomas Jefferson University, USA

Reviewed by:

Martin C. Michel,

Boehringer Ingelheim Pharma GmbH

\& Co KG, Germany

Yong $\mathrm{Li}$,

University of Pittsburgh, USA

${ }^{*}$ Correspondence:

Thomas J. Walters,

United States Army Institute of Surgical Research, Extremity Trauma and Regenerative Medicine, 3698

Chambers Pass BLDG 3611

Houston, TX 78234, USA

thomas.j.walters22.civ@mail.mil

Specialty section: This article was submitted to Integrative and Regenerative Pharmacology,

a section of the journal

Frontiers in Pharmacology

Received: 04 December 2014 Accepted: 04 April 2015 Published: 21 April 2015

Citation:

Garg K, Corona BT and Walters TJ (2015) Therapeutic strategies for preventing skeletal muscle fibrosis after injury. Front. Pharmacol. 6:87.

doi: 10.3389/fphar.2015.00087

\section{Therapeutic strategies for preventing skeletal muscle fibrosis after injury}

\author{
Koyal Garg, Benjamin T. Corona and Thomas J. Walters* \\ US Army Institute of Surgical Research, Extremity Trauma and Regenerative Medicine, Houston, TX, USA
}

Skeletal muscle repair after injury includes a complex and well-coordinated regenerative response. However, fibrosis often manifests, leading to aberrant regeneration and incomplete functional recovery. Research efforts have focused on the use of anti-fibrotic agents aimed at reducing the fibrotic response and improving functional recovery. While there are a number of mediators involved in the development of post-injury fibrosis, TGF- $\beta 1$ is the primary pro-fibrogenic growth factor and several agents that inactivate TGF- $\beta 1$ signaling cascade have emerged as promising anti-fibrotic therapies. A number of these agents are FDA approved for other conditions, clearing the way for rapid translation into clinical treatment. In this article, we provide an overview of muscle's host response to injury with special emphasis on the cellular and non-cellular mediators involved in the development of fibrosis. This article also reviews the findings of several pre-clinical studies that have utilized anti-fibrotic agents to improve muscle healing following most common forms of muscle injuries. Although some studies have shown positive results with anti-fibrotic treatment, others have indicated adverse outcomes. Some concerns and questions regarding the clinical potential of these anti-fibrotic agents have also been presented.

Keywords: TGF-B1, fibrosis, muscle injury, muscle regeneration, extracellular matrix

\section{Introduction}

According to the Armed Forces Health Surveillance Center, musculoskeletal injuries were the leading cause of medical encounters in 2010 (A.F.H.S. Center, 2011; Zambraski and Yancosek, 2012). On the battlefield, musculoskeletal trauma constitutes the majority of injuries (Owens et al., 2008). In civilian medicine muscle injuries related to sports account for $10-55 \%$ of all injuries (Garrett, 1996; Huard et al., 2002; Jarvinen et al., 2005). The poor healing responses and a high risk of reinjury presents a significant challenge to the performance of a service member or a professional athlete. The inability to effectively treat these injuries can have devastating consequences including permanent functional deficits, failed limb salvage, and delayed amputation, resulting in a tremendous toll on quality of life for the wounded personnel and their families, and also represents a great expense to the military in terms of military readiness and medical costs.

Muscle trauma can range from simple strains and contusions to severe lacerations and penetrating trauma, including volumetric muscle loss (VML) (physical loss of muscle). The ability of the skeletal muscle to regenerate depends on the type and severity of the injury. While skeletal muscle has a remarkable regenerative capacity even simple strains can heal incompletely resulting in vulnerability to reinjury (Carlson, 1986; Huard et al., 2002; Mu et al., 2010). Severe battlefield trauma involving VML is well beyond the muscles inherent capacity for self-repair (Grogan and Hsu, 2011). 
The major impediment to optimal muscle healing after any injury is fibrosis (Huard et al., 2002),defined as an abnormal and unresolvable, chronic overproliferation of extracellular matrix (ECM) components (Lieber and Ward, 2013). Fibrosis interferes with muscle regeneration (Huard et al., 2002), causes a loss in muscle function (Lieber and Ward, 2013) and alters the tissue environment causing increased susceptibility to reinjury (Carlson, 1986; Huard et al., 2002; Mu et al., 2010).

Clearly treatments aimed at improving muscle healing following injury would be of great benefit. Efforts in this area have concentrated on enhancing muscle regeneration and reducing fibrosis. Of the two, the greatest effort has been devoted to enhancing regeneration, primarily related to growth factors and/or cell-based treatments. Although optimal healing clearly involves both processes, this review will focus on therapies aimed at improving healing specifically through the reduction of fibrosis.

\section{Fibrosis: Key Players and Contributing Factors}

\section{Extracellular Matrix of Skeletal Muscle}

The muscle ECM is composed of two major layers; the basal lamina and the interstitial matrix. The basal lamina is in direct contact with the sarcolemma, and is composed primarily of type IV collagen, laminin, and heparan sulfate proteoglycans. The more abundant interstitial matrix surrounds the basal lamina and is primarily composed of collagen I, III, and V, fibronectin and perlecan (Cornelison, 2008). Structurally the ECM provides mechanical support, organization and directional guidance for nerves, vessels, and muscle cells (Sanes, 2003; Cornelison, 2008). It also provides the overall anatomical organization of the muscle: the endomysium surrounds each individual myofiber; the perimysium surrounds groups of myofibers to form fascicles; and epimysium surrounds each muscle. The perimysium contains primarily collagen I, whereas type III collagen is evenly distributed between endomysium and epimysium (Light and Champion, 1984; Gillies and Lieber, 2011).

Functionally, the ECM plays multiple roles. It is the primary contributor to the passive elastic properties of the muscle. Alterations in the amount or composition of collagen as a result of injury, diseases or aging is reflected as alterations in muscle stiffness (Lieber and Ward, 2013). The ECM and muscle fiber are coupled through intricate protein networks composed of dystroglycan and $\alpha / \beta$ integrin complexes that connect both the contractile proteins and the nucleus within the interior of the muscle fiber to the sarcolemma membrane and in turn to the basal lamina of the ECM (Jaalouk and Lammerding, 2009). These connections provide a means to transmit force from the contractile elements of individual muscle fibers to the ECM, which are in turn transmitted to the tendon and ultimately the bone (Kjaer et al., 2006). It also provides a means to transmit force laterally through providing a connection among individual neighboring muscle fibers, as well as among fascicles (Street and Ramsey, 1965; Kjaer, 2004). The protein complexes also facilitate the transduction of mechanical cues to the nucleus of the muscle and for the presentation of sequestered growth factors such as hepatocyte growth factor (HGF) and fibroblast growth factor (FGF) to the muscle (Cornelison, 2008). This cross-talk provides the requisite communication to tune the needs of the muscle to its mechanical environment for proper cell differentiation during development (Reilly and Engler, 2010) and repair (Kjaer et al., 2006), as well as for adaptation to altered physical demands (Kjaer et al., 2006).

\section{Normal vs. Aberrant Regeneration of Skeletal Muscle after Injury}

The host response to muscle injury consists of three broad phases: degeneration (1-3 days), regeneration (3-4 weeks) and remodeling (3-6 months) (Jarvinen et al., 2005; Smith et al., 2008). The degeneration phase is characterized by the disruption of muscle ultrastructure and ensuing necrosis of the damaged muscle fibers. Entry of plasma proteins and activation of the complement cascade induces chemotactic recruitment of inflammatory cells (Tidball, 2005). Plasma proteins such as fibrin cross-link and invading fibroblasts deposit collagen to form a provisional ECM matrix. This ECM matrix is transient and acts as a scaffold for the invading cells and supports the ruptured and damaged myofibers during the ongoing healing process (Middleton and Smith, 2007; Smith et al., 2008). Neutrophils are typically the first immune responders, which are gradually replaced by macrophages as the predominant inflammatory cell at the site of injury (Tidball, 2005; Tidball and Villalta, 2010). The duration and intensity of the inflammatory response after muscle injury can critically influence the regeneration process. Macrophages begin the disinfection and debridement of the wound site by phagocytosis of necrotic muscle fibers, cellular debris and microorganisms (Wynn, 2004; Smith et al., 2008; Tidball and Villalta, 2010; Wehling-Henricks et al., 2010; Wynn and Barron, 2010). This macrophage population is classified as the M1 phenotype and is pro-inflammatory. Cytokines released by the M1 macrophages (e.g., Tumor necrosis factor - alpha, interleukin (IL)-6) promote recruitment, activation and proliferation of muscle satellite cells (Torrente et al., 2003; Lolmede et al., 2009), the primary muscle precursor. The regenerative phase ensues with satellite cell proliferation, which leads to the formation of myogenic precursor cells called myoblasts which express myogenic transcription factors such as MyoD and Myf5 (Yan et al., 2003). For proper muscle healing, a shift in the macrophage phenotype from a pro-inflammatory M1 to a tissue remodeling M2 is absolutely essential (Arnold et al., 2007). M2 macrophages peak in numbers at $\sim 4$ days post injury and persist until the muscle remodeling phase (Tidball, 2005; Tidball and Villalta, 2010). M2s promote myoblast differentiation and fusion and maturation of myotubes by releasing IL-4 and IL-10. At this time the expression of myogenin, Myf4 and myocyte enhancer binding factor-2 (MEF2) is initiated (Lluis et al., 2006; Le Grand and Rudnicki, 2007; Rudnicki et al., 2008). The newly forming myotubes fuse with the existing myofibers to form new muscle tissue mature muscle fibers. The regenerative phase overlaps with the remodeling phase, in which maturation of the regenerating fibers into a functional contractile unit takes place. In the final phases of remodeling, re-organization of the ECM, revascularization and reinnervation of the myofibers 
occurs to ensure structural and functional recovery (Ciciliot and Schiaffino, 2010).

\section{The Development of Fibrosis}

ECM deposition in the wound bed can be seen within a week post-injury and it can continue on for several weeks. The predominant cell type responsible for the deposition of ECM is the fibroblast. In response to locally produced mediators such as transforming growth factor beta 1 (TGF- $\beta 1$ ), fibroblasts transform into $\alpha$-smooth muscle actin ( $\alpha$-SMA) expressing myofibroblasts (Darby et al., 1990; Desmouliere et al., 2005). These cells play a key role in wound healing and matrix deposition. Myofibroblasts can also arise from endothelial or epithelial cells or from epithelial stem cell progenitors via endothelial-mesenchymal transition. In addition, circulating $\mathrm{CD} 34^{+}$bone marrow derived progenitor cells called fibrocytes can also be recruited to the wound site to promote collagen deposition (Quan et al., 2004). Among the first synthesized ECM proteins by the myofibroblasts in the wound bed are fibronectin and tenascin-C (Hanamura et al., 1997; Tuxhorn et al., 2002), followed by collagen type III and collagen type I. As the production of collagen type I continues on for several weeks, the tensile strength of the scar tissue increases considerably (Kaariainen et al., 1998). In cases of acute and self-healing injuries (e.g., muscle strains), myofibroblasts disappear after wound closure due to apoptotic signals. But in cases of chronic injuries marked by persistent inflammation (e.g., VML), these cells do not undergo apoptosis and remain in the granulation tissue. The sustained presence and elevated numbers of immune cells in the granulation tissue promote the release of fibrogenic cytokines such as TGF- $\beta 1$. Under these conditions, myofibroblasts continue to proliferate and synthesize ECM, thus contributing to pathological scar tissue formation, referred to as fibrosis (Desmoulière et al., 2003; Moulin et al., 2004; Sarrazy et al., 2011).

ECM deposition typically proceeds more rapidly than myogenesis. If unresolved under physiological conditions, this ECM transforms into a fibrotic scar that creates a mechanical barrier and restricts the regeneration of myofibers and axons across the injury gap (Jarvinen and Lehto, 1993; Jarvinen et al., 2005, 2007). Furthermore, the fibrotic tissue lacks the elasticity of the native muscle, which can render the muscle susceptible to reinjury (Huard et al., 2002).

\section{Role of TGF- $\beta 1$ and Factors in Fibrosis and Regeneration}

Although several growth factors such as epidermal growth factor (EGF), vascular endothelial growth factor (VEGF) and FGF-2 released from neutrophils, macrophages, fibroblasts and myogenic precursors can promote fibrosis, the most pro-fibrogenic growth factor identified in the literature is TGF- $\beta 1$ (Sheppard, 2006; Serrano and Munoz-Canoves, 2010; Burks and Cohn, 2011; Mann et al., 2011; Serrano et al., 2011). In the canonical TGF- $\beta 1$ pathway, ligand binding leads to the phosphorylation of SMAD2 and SMAD3 which then bind to a common mediator SMAD4 and translocate to the nucleus to activate collagen transcription. SMAD7 suppresses this action. TGF- $\beta 1$ can also signal through the induction of non-canonical pathways including mitogen activated protein kinase (MAPK). The MAPK family consists of isoforms of extracellular signal-regulated kinases (ERKs), c-Jun $\mathrm{N}$-terminal kinase (JNKs) and p38 (Figure 1). The activation of MAPK pathway may also phosphorylate SMADs independent of the canonical TGF- $\beta 1$ pathway. Both these pathways lead to the synthesis of ECM proteins, cell proliferation, differentiation and motility. The effects of TGF- $\beta 1$ can also be mimicked and amplified by other growth factors and members of the TGF- $\beta 1$ superfamily such as connective tissue growth factor (CTGF), myostatin and platelet derived growth factor (PDGF-AA, BB) (Sheppard, 2006; Pohlers et al., 2009).

The maintenance of the ECM involves a delicate equilibrium between MMPs and their inhibitors; tissue inhibitors of metalloproteinases (TIMPs). Matrix metalloproteinases (MMPs) are endogenous zinc-dependent proteases capable of degrading ECM components. TIMPs inhibit the enzymatic activity of MMPs either by binding to the active MMPs or stabilizing the inactive forms. MMPs expressed in skeletal muscle include MMP-1, 2, 9, and 13. MMP-2 and MMP-9 are gelatinases that degrade type IV collagen, fibronectin, proteoglycans and laminin. MMP-1 and MMP-13 degrade type I and III collagen. Besides matrix destruction, MMPs also play other crucial roles in cell-to-cell communication and myogenesis (Kherif et al., 1999; Chen and Li, 2009; Gillies and Lieber, 2011).

TGF- $\beta 1$ can promote fibrosis through aberrant ECM deposition and decreased production of MMPs, thereby promoting the survival of myofibroblasts and preventing the destruction of the deposited ECM (Vaday et al., 2001; Yuan and Varga, 2001; Serrano et al., 2011). Additionally, TGF- $\beta 1$ inhibits satellite cell and myoblast proliferation and differentiation (Allen and Boxhorn, 1989; Johnson and Allen, 1990; Li et al., 2008). TGF- $\beta 1$ can also promote fibrotic cascades via the differentiation of myoblasts and muscle derived stem cells into myofibroblasts (Li et al., 2004). TGF- $\beta 1$ has anti-inflammatory functions and can switch M1 macrophages to an M2 phenotype. Macrophages of the M2 phenotype produce various growth factors such as TGF- $\beta 1$, PDGF, FGF-2, and VEGF and express high levels of arginase, which can all potentially lead to increased matrix production (WehlingHenricks et al., 2010). In contradiction, other studies have suggested that $\mathrm{M} 2 \mathrm{~s}$ are required for the suppression and resolution of fibrosis because they can also stimulate the production of collagen degrading MMPs and IL-10 (Pesce et al., 2009; Wynn and Ramalingam, 2012). A recent study showed that exogenous therapy of M1 macrophages reduced fibrosis and enhanced muscle fiber regeneration in lacerated muscles (Novak et al., 2014). Thus, macrophages play very complex roles in regeneration and are capable of both inducing and inhibiting fibrosis (Wynn, 2004; Wynn and Barron, 2010; Murray and Wynn, 2011).

\section{Anti-Fibrotic Therapies}

The dominant role of TGF- $\beta 1$ makes it an obvious target for anti-fibrotic treatments and several agents that inactivate TGF- $\beta 1$ signaling cascade have emerged as promising therapies. Table 1 provides an overview of the existing agents in the literature. The focus of this review article is on muscle injury. Therefore, the 


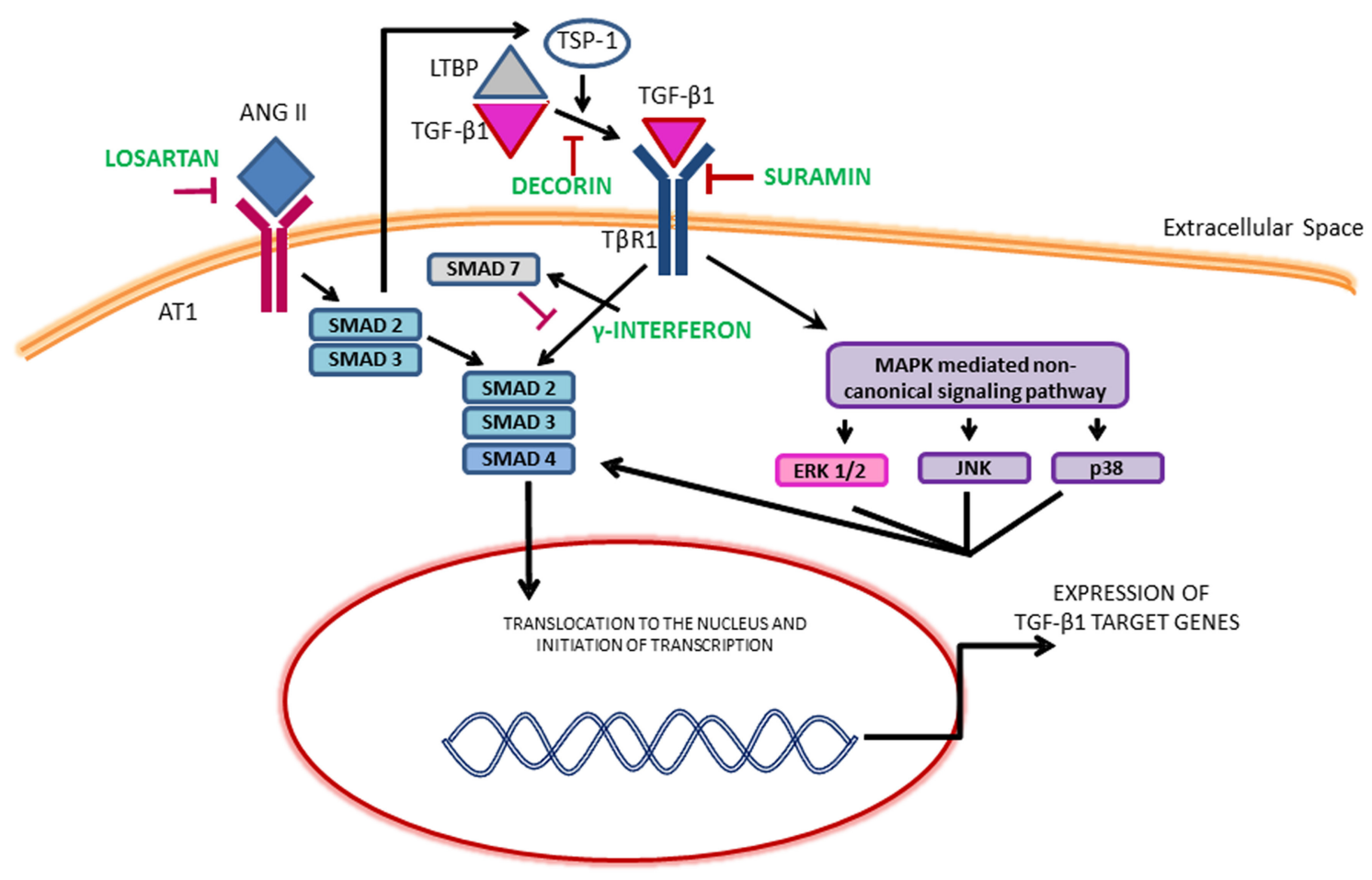

FIGURE 1 | Illustration of the TGF- $\boldsymbol{\beta} 1$ signaling pathways and the mechanism of therapeutics. ERK, Extracellular signal regulated kinase; JNK, C-Jun N-terminal kinase; LTBP, Latent transforming growth factor binding proteins; MAPKs, Mitogen-activated protein kinase; TSP-1, Thrombospondin-1.

readers are referred elsewhere for information on anti-fibrotic agents aimed at muscle diseases (e.g., pirfenidone) (Burks and Cohn, 2011). Losartan is an FDA approved antihypertensive medication that acts by blocking angiotensin II type 1 receptor (AT1) (Figure 1). Activation of the AT1 receptor by angiotensin produces thrombospondin -1 (TSP-1), which is a key regulator of latent TGF- $\beta 1$ activation. Losartan is an inhibitor of AT1 activation and indirectly blocks TGF- $\beta 1$ activation by inhibiting TSP-1 production (Chamberlain, 2007). Losartan has been shown to attenuate TGF- $\beta 1$ signaling in chronic renal disease, cardiomyopathies and marfan syndrome (Cohn et al., 2007). The optimal healing dose of losartan for muscle healing coincides with the clinically relevant safe human dose of $10 \mathrm{mg} / \mathrm{kg} / \mathrm{day}$, which is easily administered in drinking water of rodents (Kobayashi et al., 2013).

Losartan has been shown to reduce the fibrotic area, improve muscle regeneration and improve muscle function in murine models of contusion (Kobayashi et al., 2013) and laceration (Bedair et al., 2008). However, the timing of administration is critical. Beneficial effects occur when administration begins on day 3 or 7 post-injury. In contrast, immediate administration results in aberrant regeneration, likely attributable to disruption of the initial inflammatory response and the natural healing process of skeletal muscle (Kobayashi et al., 2013). The anti-fibrotic effect of losartan has also been combined with other regenerative therapies in quest to further improve skeletal muscle healing. Losartan treatment has been shown to significantly improve the myogenic potential of transplanted ASCs (Park et al., 2012).
Losartan combined with platelet rich plasma (PRP) significantly reduced fibrosis and improved function in a mouse contusion model compared to PRP alone (Terada et al., 2013). Although PRP presents a promising regenerative therapy (Sanchez et al., 2014), some researchers have raised concerns about the PRPderived TGF- $\beta$ in fibrotic remodeling of injured muscle (Robi and Matjaz, 2014). Regardless, these initial studies suggest that optimal treatment of muscle must consider the interactions of fibrosis and muscle regeneration. Although losartan is well tolerated, the side-effects include hypotension, headache, dizziness, fatigue, cholestatic hepatitis, raised liver enzymes and pancreatitis (Aronson, 2009).

Suramin is FDA approved as an anti-parasitic and antineoplastic agent that can inhibit several growth factors including TGF- $\beta 1$ by competitively binding to their receptors (Chan et al., 2003). Intramuscular injection of suramin after injury caused by contusion (Nozaki et al., 2008, 2012), laceration (Chan et al., 2003) and strain (Chan et al., 2005) reduces fibrosis and improves functional recovery (Chan et al., 2003; Nozaki et al., 2008). Additionally, suramin also inhibits myostatin expression (Chan et al., 2005). The side-effects associated with suramin use include malaise, neuropathy, mineral corticoid insufficiency, corneal deposits, occasional thrombocytopenia, neutropenia and renal failure (Chan et al., 2005).

Gamma interferon ( $\gamma$-INF) has also been shown to disrupt TGF- $\beta 1$ signaling by upregulating smad7 expression and is approved by the FDA to treat hepatic fibrosis (Foster et al., 2003). In a mouse laceration model, $\gamma$-INF was shown to decrease 


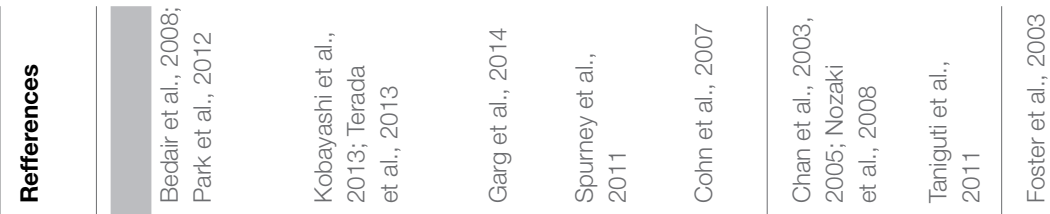

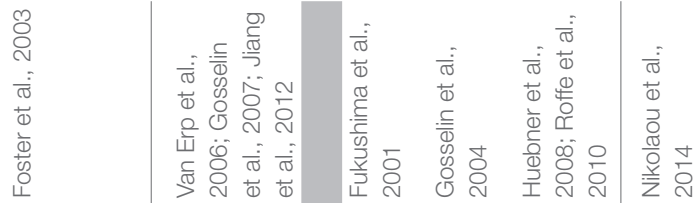
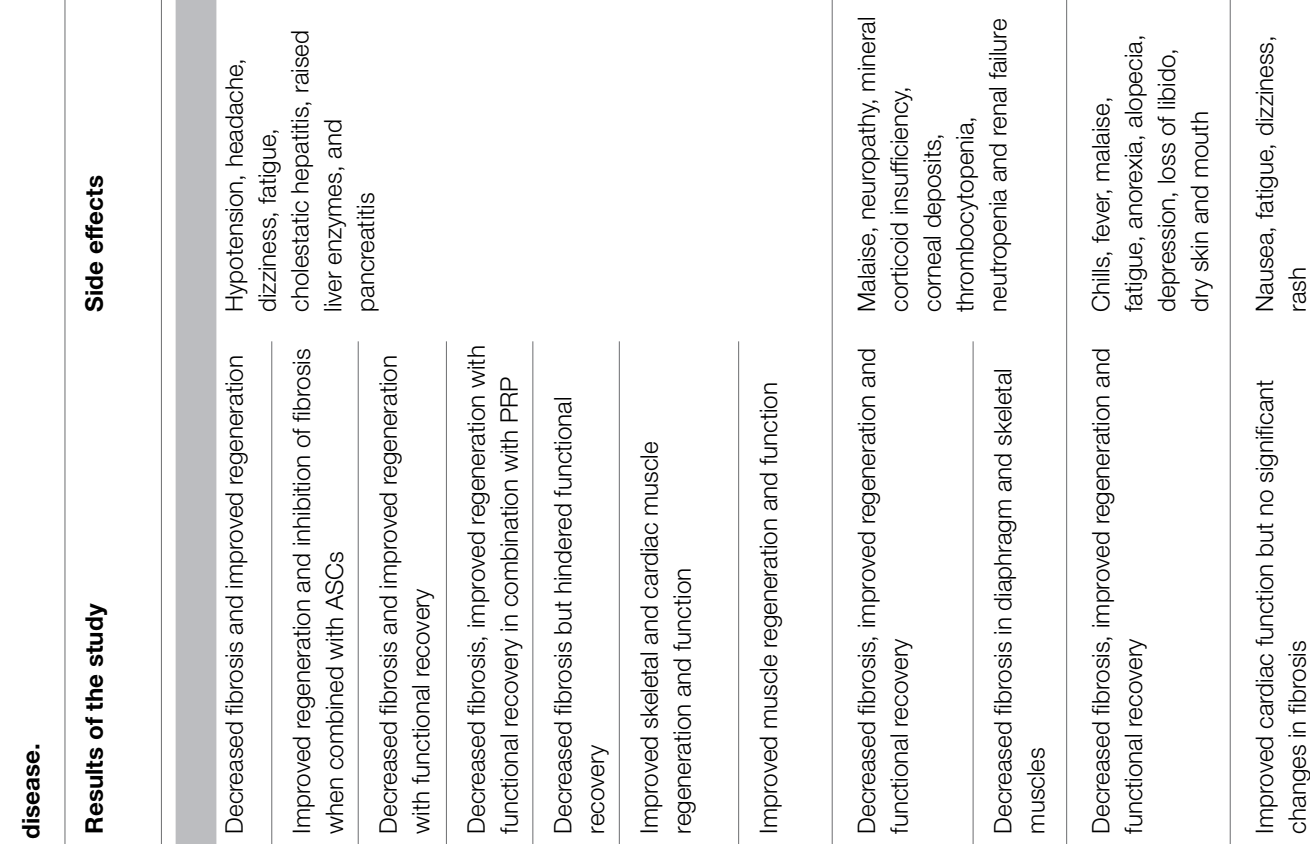

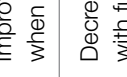

总突

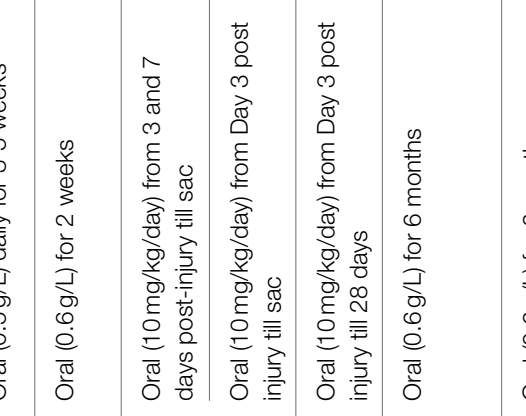

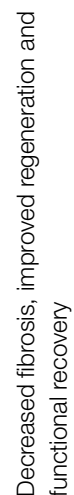

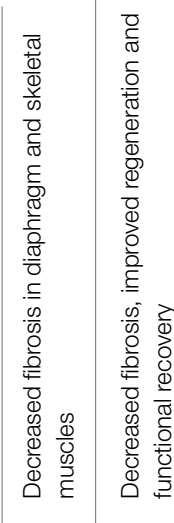

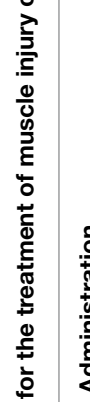

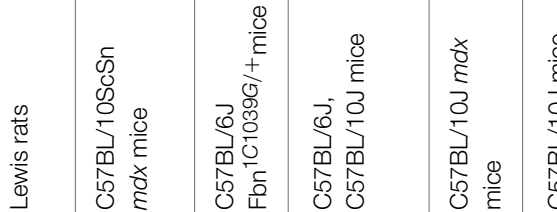

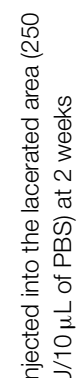

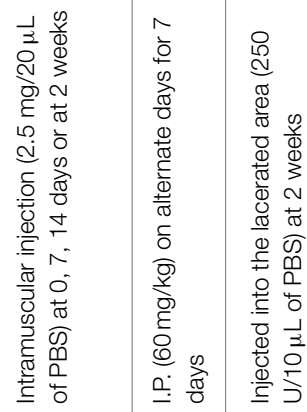
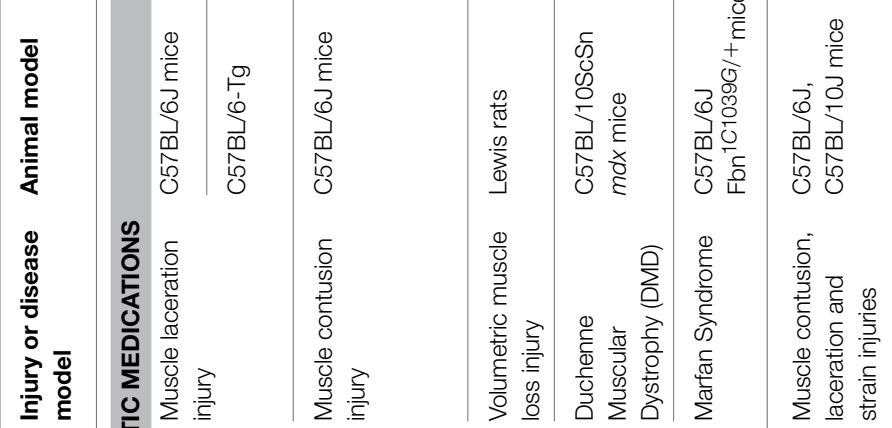

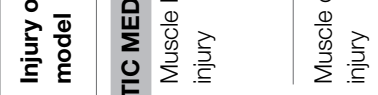

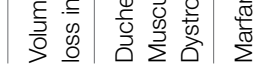
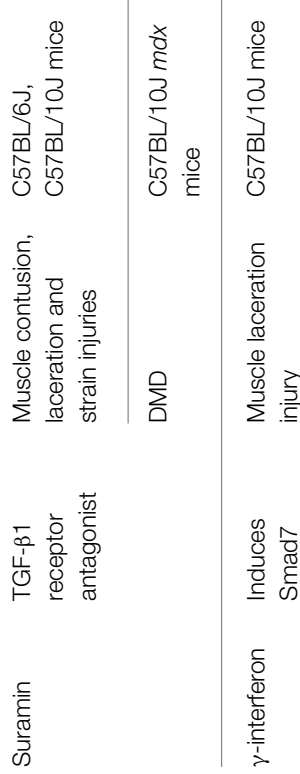
fibrosis and improve muscle strength. The side effects of this drug include chills, fever, malaise, fatigue, anorexia, alopecia, depression, loss of libido and dry skin and mouth (Friedlander et al., 1996).

The proteoglycan decorin can bind to TGF- $\beta 1$, preventing association with its receptor (Li et al., 2004), and has anti-fibrotic effects in kidney, liver and lung (Dreher et al., 1990; Isaka et al., 1996; Giri et al., 1997). It reduces fibrosis, and enhances muscle regeneration and function following muscle laceration in mice (Fukushima et al., 2001). Decorin has also been used in combination with IGF-1 in an attempt to reduce fibrosis and also enhance muscle regeneration. In a murine muscle laceration model the combination had an additive effect histologically. However, the results were not translated to an improvement in muscle function (Sato et al., 2003). The anti-fibrotic halofuginone has been shown to reduce fibrosis by reducing SMAD 3 phosphorylation. In a model of neonatal brachial plexus injury, $0.3 \mu \mathrm{g} / \mathrm{g}$ of halofuginone administration three times a week for 4 weeks decreased biceps fibrosis but did not reduce contracture severity (Nikolaou et al., 2014).

Other approaches for reducing muscle fibrosis after injury include MMP treatment. It was found that administration of recombinant human MMP-1 at day 33 post-laceration was effective in reducing muscle fibrosis (Kaar et al., 2008). It has also been suggested that increase in the activity of MMP- 3 and MMP- 9 by osteoactivin (a type 1 glycoprotein expressed in myofibers) is useful for attenuating skeletal muscle fibrosis caused by denervation and distraction osteogenesis (Furochi et al., 2007; Tonogai et al., 2014).

\section{Concerns and Future Directions}

Unlike fibrosis, the increased collagen deposition is a normal response to altered demand including submaximal aerobic exercise (Miller et al., 2005), strength and resistance training (Moore et al., 2005; Heinemeier et al., 2007), and stretching (Stauber et al., 1996). In these cases, increased collagen deposition is a positive adaptive response that protects the muscle from strain injury and provides a means to improve lateral force transmission (Stauber et al., 1996; Gillies and Lieber, 2011). The increase in collagen deposition following these activities is largely affected by increased TGF- $\beta$ and many of the same signals that stimulate collagen production also orchestrate positive adaptation within the myofibrils under these conditions. What remains unexplored is the interaction of anti-fibrotic treatment with the response to muscular activity, e.g., physical therapy.

There is also evidence that increased collagen deposition can also be beneficial response to certain forms of muscle injury. Some studies have challenged the concept of preventing fibrosis by blocking TGF- $\beta$ signaling following muscle injury. Lieber and co-workers have suggested that the development of skeletal muscle fibrosis in response to nesprin and desmin deletion is a compensatory mechanism that protects muscle fiber from injury due to excessive strains (Meyer and Lieber, 2012; Chapman et al., 2014).

Gumucio et al. have demonstrated that inhibition of TGF$\beta$ using a bio-neutralizing antibody initially improved force production following eccentric contraction injury, however, it ultimately led to long-term force deficit (Gumucio et al., 2013). Recent work from our laboratory involving VML injury, a particularly severe form of muscle injury in which a portion of the muscle has been frank lost, demonstrated that the formation of a fibrotic scar partially restores muscle function (Nikolaou et al., 2014). Furthermore, accelerating scar formation through surgical repair and transplantation of an acellular ECM (Chen and Walters, 2013; Corona et al., 2013) or through exercise (Aurora et al., 2014), is accompanied by an improvement in muscle function. Conversely, muscle function is dramatically reduced when collagen deposition is delayed or reduced by the administration of losartan (Garg et al., 2014). In the unique case of VML injury, the development of a fibrotic scar at the wound site provides a means to transmit force between intact areas of muscle by providing a physical bridge. Additionally, the presence of scar at the wound site shields the remaining muscle from increased loading secondary to VML (Corona et al., 2013). Clearly, VML represents an extreme form of muscle injury, however, this work underlines the need to consider the type and magnitude of the injury when exploring anti-fibrotic treatments. TGF- $\beta 1$ is a multi-functional growth factor with roles in inflammation, immunomodulation, wound healing and fibrosis (Kulkarni et al., 1993; Andreetta et al., 2006). Therefore, it is required to evaluate the long-term effects of anti-fibrotic therapies targeting TGF- $\beta 1$ on immunomodulation. Systemic and prolonged attenuation of TGF- $\beta 1$ may also lead to massive multi-organ inflammation and autoimmunity (Andreetta et al., 2006). Similarly, anti-fibrotic therapies such as $\gamma$-INF and halofuginone act downstream on the SMADs (Figure 1). SMADs are involved in a variety of different pathways besides fibrosis and interfering with their action could lead to undesirable effects (Rodriguez-Vita et al., 2005; Goldstein et al., 2011).

\section{Clinical Translation}

The translation of animal studies involving anti-fibrotic agents for muscle injury into human studies and clinical trials has been extremely limited. In fact, with the exception of a single case report involving the treatment of a muscle strain injury with losartan (Gharaibeh et al., 2012), we are unaware of any other human studies involving the treatment of muscle injury with an anti-fibrotic treatment. Clinically, muscle is viewed as a regenerative tissue and patients presenting with muscle injuries often do not receive medical treatment beyond R.I.C.E and some form of anti-inflammatory medication (Gharaibeh et al., 2012). Anti-fibrotic agents hold promise as advance in the treatment of muscle injury, however their potential side effects and possible disruption of normal adaptive responses represent a valid concern. While life-threating fibrotic diseases such as idiopathic pulmonary fibrosis and muscular dystrophy may warrant the potential adverse side effects of anti-fibrotic drugs, it is not clear where along the continuum of muscle injury the risk becomes worth the potential reward.

\section{Conclusion}

Skeletal muscle repair following injury includes a complex and well-coordinated regenerative response. However, fibrosis 
often manifest, leading to aberrant regeneration and incomplete functional recovery. In general, preclinical animal studies have demonstrated improvements in muscle injuries with antifibrotic treatments. However, there remain a number of unanswered questions that will need to be addressed in order to refine our understanding of anti-fibrotic treatments and before their clinical potential is realized. For example: What is the optimal time to initiate treatment? What types of muscle injuries are most amenable to anti-fibrotic treatment, e.g. strain injures vs. VML injury? And do anti-fibrotic drugs impact the normal adaptive response of muscle to increased activity, therefore hindering

\section{References}

A.F.H.S. Center. (2011). Brief Report: Morbidity Burden to Attributable to Illnesses and Injuries in Deployed (per Theater Medical Data Store TMDS) Compared to Nondeployed (per Defense Medical Surveillance System DMSS) Settings, Active Component, Vol. 18. Silver Spring, MD: U.S. Armed Forces. MSMR.

Allen, R. E., and Boxhorn, L. K. (1989). Regulation of skeletal muscle satellite cell proliferation and differentiation by transforming growth factor-beta, insulinlike growth factor I, and fibroblast growth factor. J. Cell. Physiol. 138, 311-315. doi: $10.1002 /$ jcp. 1041380213

Andreetta, F., Bernasconi, P., Baggi, F., Ferro, P., Oliva, L., Arnoldi, E., et al. (2006). Immunomodulation of TGF-beta 1 in $\mathrm{mdx}$ mouse inhibits connective tissue proliferation in diaphragm but increases inflammatory response: implications for antifibrotic therapy. J. Neuroimmunol. 175, 77-86. doi: 10.1016/j.jneuroim.2006.03.005

Arnold, L., Henry, A., Poron, F., Baba-Amer, Y., van Rooijen, N., Plonquet, A., et al. (2007). Inflammatory monocytes recruited after skeletal muscle injury switch into antiinflammatory macrophages to support myogenesis. J. Exp. Med. 204, 1057-1069. doi: 10.1084/jem.20070075

Aronson, J. K. (2009). Meyler's Side Effects of Cardiovascular Drugs. San Diego, CA: Elsevier.

Aurora, A., Garg, K., Corona, B. T., and Walters, T. J. (2014). Physical rehabilitation improves muscle function following volumetric muscle loss injury. $B M C$ Sports Sci. Med. Rehabil. 6:41. doi: 10.1186/2052-1847-6-41

Bedair, H. S., Karthikeyan, T., Quintero, A., Li, Y., and Huard, J. (2008). Angiotensin II receptor blockade administered after injury improves muscle regeneration and decreases fibrosis in normal skeletal muscle. Am. J. Sports Med. 36, 1548-1554. doi: 10.1177/0363546508315470

Burks, T. N., and Cohn, R. D. (2011). Role of TGF-beta signaling in inherited and acquired myopathies. Skelet. Muscle 1:19. doi: 10.1186/2044-5040-1-19

Carlson, B. M. (1986). Regeneration of entire skeletal muscles. Fed. Proc. 45, 1456-1460.

Chamberlain, J. S. (2007). ACE inhibitor bulks up muscle. Nat. Med. 13, 125-126. doi: $10.1038 / \mathrm{nm} 0207-125$

Chan, Y. S., Li, Y., Foster, W., Fu, F. H., and Huard, J. (2005). The use of suramin, an antifibrotic agent, to improve muscle recovery after strain injury. Am. J. Sports Med. 33, 43-51. doi: 10.1177/0363546504265190

Chan, Y. S., Li, Y., Foster, W., Horaguchi, T., Somogyi, G., Fu, F. H., et al. (2003). Antifibrotic effects of suramin in injured skeletal muscle after laceration. J. Appl. Physiol. 95, 771-780. doi: 10.1152/japplphysiol.009 15.2002

Chapman, M. A., Zhang, J., Banerjee, I., Guo, L. T., Zhang, Z., Shelton, G. D., et al. (2014). Disruption of both nesprin 1 and desmin results in nuclear anchorage defects and fibrosis in skeletal muscle. Hum. Mol. Genet. 23, 5879-5892. doi: $10.1093 / \mathrm{hmg} / \mathrm{ddu} 310$

Chen, X., and Li, Y. (2009). Role of matrix metalloproteinases in skeletal muscle: migration, differentiation, regeneration and fibrosis. Cell Adh. Migr. 3, 337-341. doi: $10.4161 / \mathrm{cam} .3 .4 .9338$

Chen, X. K., and Walters, T. J. (2013). Muscle-derived decellularised extracellular matrix improves functional recovery in a rat latissimus dorsi muscle defect model. J. Plast. Reconst. Aesthet. Surg. 66, 1750-1758. doi: 10.1016/j.bjps.2013.07.037 long-term healing? While a number of potential treatments are FDA approved for other indications, clinical trials in human volunteers will be important in addressing concerns regarding potential side effects, particularly in regard to balancing cost vs. benefit of anti-fibrotic treatments. Finally, although anti-fibrotic treatments improve muscle healing in the majority of the studies reviewed, they do not result in complete muscle regeneration. To this end, recent studies combining anti-fibrotic treatments with cell-based therapies have provided exciting evidence that the optimal treatment of muscle injuries may lay in a multifactorial approach to treating muscle injuries.
Ciciliot, S., and Schiaffino, S. (2010). Regeneration of mammalian skeletal muscle. Basic mechanisms and clinical implications. Curr. Pharm. Des. 16, 906-914. doi: $10.2174 / 138161210790883453$

Cohn, R. D., van Erp, C., Habashi, J. P., Soleimani, A. A., Klein, E. C., Lisi, M. T., et al. (2007). Angiotensin II type 1 receptor blockade attenuates TGF-betainduced failure of muscle regeneration in multiple myopathic states. Nat. Med. 13, 204-210. doi: $10.1038 / \mathrm{nm} 1536$

Cornelison, D. D. (2008). Context matters: in vivo and in vitro influences on muscle satellite cell activity. J. Cell. Biochem. 105, 663-669. doi: 10.1002/jcb.21892

Corona, B. T., Wu, X., Ward, C. L., McDaniel, J. S., Rathbone, C. R., and Walters, T. J. (2013). The promotion of a functional fibrosis in skeletal muscle with volumetric muscle loss injury following the transplantation of muscle-ECM. Biomaterials 34, 3324-3335. doi: 10.1016/j.biomaterials.2013.01.061

Darby, I., Skalli, O., and Gabbiani, G. (1990). Alpha-smooth muscle actin is transiently expressed by myofibroblasts during experimental wound healing. Laboratory investigation. J. Tech. Methods Pathol. 63, 21-29.

Desmouliere, A., Chaponnier, C., and Gabbiani, G. (2005). Tissue repair, contraction, and the myofibroblast. Wound Repair Regen. 13, 7-12. doi: 10.1111/j.10671927.2005.130102.x

Desmoulière, A., Darby, I. A., and Gabbiani, G. (2003). Normal and pathologic soft tissue remodeling: role of the myofibroblast, with special emphasis on liver and kidney fibrosis. Lab. Invest. 83, 1689-1707. doi: 10.1097/01.LAB.0000101911.53973.90

Dreher, K. L., Asundi, V., Matzura, D., and Cowan, K. (1990). Vascular smooth muscle biglycan represents a highly conserved proteoglycan within the arterial wall. Eur. J. Cell Biol. 53, 296-304.

Foster, W., Li, Y., Usas, A., Somogyi, G., and Huard, J. (2003). Gamma interferon as an antifibrosis agent in skeletal muscle. J. Orthop. Res. 21, 798-804. doi: 10.1016/S0736-0266(03)00059-7

Friedlander, L., van Thiel, D. H., Faruki, H., Molloy, P. J., Kania, R. J., and Hassanein, T. (1996). New approach to HCV treatment. Recognition of disease process as systemic viral infection rather than as liver disease. Dig. Dis. Sci. 41, 1678-1681. doi: 10.1007/BF02087924

Fukushima, K., Badlani, N., Usas, A., Riano, F., Fu, F., and Huard, J. (2001). The use of an antifibrosis agent to improve muscle recovery after laceration. Am. J. Sports Med. 29, 394-402. doi: 10.1177/03635465010290040201

Furochi, H., Tamura, S., Takeshima, K., Hirasaka, K., Nakao, R., Kishi, K., et al. (2007). Overexpression of osteoactivin protects skeletal muscle from severe degeneration caused by long-term denervation in mice. J. Med. Invest. 54, 248-254. doi: 10.2152/jmi.54.248

Garg, K., Corona, B. T., and Walters, T. J. (2014). Losartan administration reduces fibrosis but hinders functional recovery after volumetric muscle loss injury. J. Appl. Physiol. 117, 1120-1131. doi: 10.1152/japplphysiol.00689.2014

Garrett, W. E. Jr. (1996). Muscle strain injuries. Am. J. Sports Med. 24, S2-S8.

Gharaibeh, B., Chun-Lansinger, Y., Hagen, T., Ingham, S. J., Wright, V., Fu, F., et al. (2012). Biological approaches to improve skeletal muscle healing after injury and disease. Birth Defects Res. C Embryo Today 96, 82-94. doi: 10.1002/bdrc. 21005

Gillies, A. R., and Lieber, R. L. (2011). Structure and function of the skeletal muscle extracellular matrix. Muscle Nerve 44, 318-331. doi: 10.1002/mus.22094

Giri, S. N., Hyde, D. M., Braun, R. K., Gaarde, W., Harper, J. R., and Pierschbacher, M. D. (1997). Antifibrotic effect of decorin in a bleomycin hamster 
model of lung fibrosis. Biochem. Pharmacol. 54, 1205-1216. doi: 10.1016/S00062952(97)00343-2

Goldstein, J. A., Kelly, S. M., LoPresti, P. P., Heydemann, A., Earley, J. U., Ferguson, E. L., et al. (2011). SMAD signaling drives heart and muscle dysfunction in a Drosophila model of muscular dystrophy. Hum. Mol. Genet. 20, 894-904. doi: $10.1093 / \mathrm{hmg} / \mathrm{ddq} 528$

Gosselin, L. E., Williams, J. E., Deering, M., Brazeau, D., Koury, S., and Martinez, D. A. (2004). Localization and early time course of TGF-beta 1 mRNA expression in dystrophic muscle. Muscle Nerve 30, 645-653. doi: 10.1002/mus. 20150

Gosselin, L. E., Williams, J. E., Personius, K., and Farkas, G. A. (2007). A comparison of factors associated with collagen metabolism in different skeletal muscles from dystrophic (mdx) mice: impact of pirfenidone. Muscle Nerve 35, 208-216. doi: $10.1002 /$ mus.20681

Grogan, B. F., and Hsu, J. R. (2011). Volumetric muscle loss. J. Am. Acad. Orthop. Surg. 19(Suppl. 1), S35-S37.

Gumucio, J. P., Flood, M. D., Phan, A. C., Brooks, S. V., and Mendias, C. L. (2013). Targeted inhibition of TGF-beta results in an initial improvement but long-term deficit in force production after contraction-induced skeletal muscle injury. J. Appl. Physiol. 115, 539-545. doi: 10.1152/japplphysiol.00374.2013

Hanamura, N., Yoshida, T., Matsumoto, E., Kawarada, Y., and Sakakura, T. (1997). Expression of fibronectin and tenascin-C mRNA by myofibroblasts, vascular cells and epithelial cells in human colon adenomas and carcinomas. Int. J. Cancer 73, 10-15.

Heinemeier, K. M., Olesen, J. L., Haddad, F., Langberg, H., Kjaer, M., Baldwin, K. M., et al. (2007). Expression of collagen and related growth factors in rat tendon and skeletal muscle in response to specific contraction types. J. Physiol. 582, 1303-1316. doi: 10.1113/jphysiol.2007.127639

Huard, J., Li, Y., and Fu, F. H. (2002). Muscle injuries and repair: current trends in research. J. Bone Joint Surg. Am. 84-A, 822-832.

Huebner, K. D., Jassal, D. S., Halevy, O., Pines, M., and Anderson, J. E. (2008). Functional resolution of fibrosis in $\mathrm{mdx}$ mouse dystrophic heart and skeletal muscle by halofuginone. Am. J. Physiol. Heart Circ. Physiol. 294, H1550-H1561. doi: 10.1152/ajpheart.01253.2007

Isaka, Y., Brees, D. K., Ikegaya, K., Kaneda, Y., Imai, E., Noble, N. A., et al. (1996). Gene therapy by skeletal muscle expression of decorin prevents fibrotic disease in rat kidney. Nat. Med. 2, 418-423. doi: 10.1038/nm0496-418

Jaalouk, D. E., and Lammerding, J. (2009). Mechanotransduction gone awry. Nat. Rev. Mol. Cell Biol. 10, 63-73. doi: 10.1038/nrm2597

Jarvinen, M. J., and Lehto, M. U. (1993). The effects of early mobilisation and immobilisation on the healing process following muscle injuries. Sports Med. 15, 78-89. doi: 10.2165/00007256-199315020-00002

Jarvinen, T. A., Jarvinen, T. L., Kaariainen, M., Aarimaa, V., Vaittinen, S., Kalimo, H., et al. (2007). Muscle injuries: optimising recovery. Best Pract. Res. Clin. Rheumatol. 21, 317-331. doi: 10.1016/j.berh.2006.12.004

Jarvinen, T. A., Jarvinen, T. L., Kaariainen, M., Kalimo, H., and Jarvinen, M. (2005). Muscle injuries: biology and treatment. Am. J. Sports Med. 33, 745-764. doi: 10.1177/0363546505274714

Jiang, C., Huang, H., Liu, J., Wang, Y., Lu, Z., and Xu, Z. (2012). Adverse events of pirfenidone for the treatment of pulmonary fibrosis: a metaanalysis of randomized controlled trials. PLoS ONE 7:e47024. doi: 10.1371/journal.pone.0047024

Johnson, S. E., and Allen, R. E. (1990). The effects of bFGF, IGF-I, and TGF-beta on RMo skeletal muscle cell proliferation and differentiation. Exp. Cell Res. 187, 250-254. doi: 10.1016/0014-4827(90)90088-R

Kaar, J. L., Li, Y., Blair, H. C., Asche, G., Koepsel, R. R., Huard, J., et al. (2008). Matrix metalloproteinase-1 treatment of muscle fibrosis. Acta Biomater. 4, 1411-1420. doi: 10.1016/j.actbio.2008.03.010

Kaariainen, M., Kaariainen, J., Jarvinen, T. L., Sievanen, H., Kalimo, H., and Jarvinen, M. (1998). Correlation between biomechanical and structural changes during the regeneration of skeletal muscle after laceration injury. J. Orthop. Res. 16, 197-206. doi: 10.1002/jor.1100160207

Kherif, S., Lafuma, C., Dehaupas, M., Lachkar, S., Fournier, J. G., VerdiereSahuque, M., et al. (1999). Expression of matrix metalloproteinases 2 and 9 in regenerating skeletal muscle: a study in experimentally injured and $\mathrm{mdx}$ muscles. Dev. Biol. 205, 158-170. doi: 10.1006/dbio.1998.9107

Kjaer, M. (2004). Role of extracellular matrix in adaptation of tendon and skeletal muscle to mechanical loading. Physiol. Rev. 84, 649-698. doi: 10.1152/physrev.00031.2003
Kjaer, M., Magnusson, P., Krogsgaard, M., Boysen Moller, J., Olesen, J., Heinemeier, K., et al. (2006). Extracellular matrix adaptation of tendon and skeletal muscle to exercise. J. Anat. 208, 445-450. doi: 10.1111/j.14697580.2006.00549.x

Kobayashi, T., Uehara, K., Ota, S., Tobita, K., Ambrosio, F., Cummins, J. H., et al. (2013). The timing of administration of a clinically relevant dose of losartan influences the healing process after contusion induced muscle injury. J. Appl. Physiol. 114, 262-273. doi: 10.1152/japplphysiol.00140.2011

Kulkarni, A. B., Huh, C. G., Becker, D., Geiser, A., Lyght, M., Flanders, K. C., et al. (1993). Transforming growth factor beta 1 null mutation in mice causes excessive inflammatory response and early death. Proc. Natl. Acad. Sci. U.S.A. 90, 770-774. doi: 10.1073/pnas.90.2.770

Le Grand, F., and Rudnicki, M. A. (2007). Skeletal muscle satellite cells and adult myogenesis. Curr. Opin. Cell Biol. 19, 628-633. doi: 10.1016/j.ceb.2007.09.012

Li, X., McFarland, D. C., and Velleman, S. G. (2008). Effect of Smad3-mediated transforming growth factor-betal signaling on satellite cell proliferation and differentiation in chickens. Poult. Sci. 87, 1823-1833. doi: 10.3382/ps.200800133

Li, Y., Foster, W., Deasy, B. M., Chan, Y., Prisk, V., Tang, Y., et al. (2004). Transforming growth factor-betal induces the differentiation of myogenic cells into fibrotic cells in injured skeletal muscle: a key event in muscle fibrogenesis. Am. J. Pathol. 164, 1007-1019. doi: 10.1016/S0002-9440(10)63188-4

Lieber, R. L., and Ward, S. R. (2013). Cellular mechanisms of tissue fibrosis. 4. Structural and functional consequences of skeletal muscle fibrosis. Am. J. Physiol. Cell Physiol. 305, C241-C252. doi: 10.1152/ajpcell.00173.2013

Light, N., and Champion, A. E. (1984). Characterization of muscle epimysium, perimysium and endomysium collagens. Biochem. J. 219, 1017-1026.

Lluis, F., Perdiguero, E., Nebreda, A. R., and Munoz-Canoves, P. (2006). Regulation of skeletal muscle gene expression by p38 MAP kinases. Trends Cell Biol. 16, 36-44. doi: 10.1016/j.tcb.2005.11.002

Lolmede, K., Campana, L., Vezzoli, M., Bosurgi, L., Tonlorenzi, R., Clementi, E., et al. (2009). Inflammatory and alternatively activated human macrophages attract vessel-associated stem cells, relying on separate HMGB1- and MMP-9dependent pathways. J. Leukoc. Biol. 85, 779-787. doi: 10.1189/jlb.0908579

Mann, C. J., Perdiguero, E., Kharraz, Y., Aguilar, S., Pessina, P., Serrano, A. L., et al. (2011). Aberrant repair and fibrosis development in skeletal muscle. Skelet. Muscle 1:21. doi: 10.1186/2044-5040-1-21

Meyer, G. A., and Lieber, R. L. (2012). Skeletal muscle fibrosis develops in response to desmin deletion. Am. J. Physiol. Cell Physiol. 302, C1609-C1620. doi: 10.1152/ajpcell.00441.2011

Middleton, S., and Smith, J. (2007). Muscle injuries. Trauma 9, 5-11. doi: $10.1177 / 1460408607081918$

Miller, B. F., Olesen, J. L., Hansen, M., Dossing, S., Crameri, R. M., Welling, R. J., et al. (2005). Coordinated collagen and muscle protein synthesis in human patella tendon and quadriceps muscle after exercise. J. Physiol. 567, 1021-1033. doi: 10.1113/jphysiol.2005.093690

Moore, D. R., Phillips, S. M., Babraj, J. A., Smith, K., and Rennie, M. J. (2005). Myofibrillar and collagen protein synthesis in human skeletal muscle in young men after maximal shortening and lengthening contractions. Am. J. Physiol. Endocrinol. Metab. 288, E1153-E1159. doi: 10.1152/ajpendo.00387.2004

Moulin, V., Larochelle, S., Langlois, C., Thibault, I., Lopez-Valle, C. A., and Roy, M. (2004). Normal skin wound and hypertrophic scar myofibroblasts have differential responses to apoptotic inductors. J. Cell. Physiol. 198, 350-358. doi: 10.1002/jcp. 10415

Mu, X., Bellayr, I., Walters, T., and Li, Y. (2010). Mediators leading to fibrosis how to measure and control them in tissue engineering. Oper. Tech. Orthop. 20, 110-118. doi: 10.1053/j.oto.2009.10.003

Murray, P. J., and Wynn, T. A. (2011). Protective and pathogenic functions of macrophage subsets. Nat. Rev. Immunol. 11, 723-737. doi: 10.1038/nri3073

Nikolaou, S., Liangjun, H., Tuttle, L. J., Weekley, H., Christopher, W., Lieber, R. L., et al. (2014). Contribution of denervated muscle to contractures after neonatal brachial plexus injury: not just muscle fibrosis. Muscle Nerve 49, 398-404. doi: 10.1002/mus.23927

Novak, M. L., Weinheimer-Haus, E. M., and Koh, T. J. (2014). Macrophage activation and skeletal muscle healing following traumatic injury. J. Pathol. 232, 344-355. doi: 10.1002/path.4301

Nozaki, M., Li, Y., Zhu, J., Ambrosio, F., Uehara, K., Fu, F. H., et al. (2008). Improved muscle healing after contusion injury by the inhibitory effect of 
suramin on myostatin, a negative regulator of muscle growth. Am. J. Sports Med. 36, 2354-2362. doi: 10.1177/0363546508322886

Nozaki, M., Ota, S., Terada, S., Li, Y., Uehara, K., Gharaibeh, B., et al. (2012). Timing of the administration of suramin treatment after muscle injury. Muscle Nerve 46, 70-79. doi: 10.1002/mus. 23280

Owens, B. D., Kragh, J. F. Jr., Wenke, J. C., Macaitis, J., Wade, C. E., and Holcomb, J. B. (2008). Combat wounds in operation Iraqi Freedom and operation Enduring Freedom. J. Trauma 64, 295-299. doi: 10.1097/TA.0b013e318163b875

Park, J. K., Ki, M. R., Lee, E. M., Kim, A. Y., You, S. Y., Han, S. Y., et al. (2012). Losartan improves adipose tissue-derived stem cell niche by inhibiting transforming growth factor-beta and fibrosis in skeletal muscle injury. Cell Transplant. 21, 2407-2424. doi: 10.3727/096368912X637055

Pesce, J. T., Ramalingam, T. R., Mentink-Kane, M. M., Wilson, M. S., El Kasmi, K. C., Smith, A. M., et al. (2009). Arginase-1-expressing macrophages suppress Th2 cytokine-driven inflammation and fibrosis. PLoS Pathog. 5:e1000371. doi: 10.1371/journal.ppat.1000371

Pohlers, D., Brenmoehl, J., Loffler, I., Muller, C. K., Leipner, C., SchultzeMosgau, S., et al. (2009). TGF-beta and fibrosis in different organs molecular pathway imprints. Biochim. Biophys. Acta 1792, 746-756. doi: 10.1016/j.bbadis.2009.06.004

Quan, T. E., Cowper, S., Wu, S. P., Bockenstedt, L. K., and Bucala, R. (2004). Circulating fibrocytes: collagen-secreting cells of the peripheral blood. Int. J. Biochem. Cell Biol. 36, 598-606. doi: 10.1016/j.biocel.2003.10.005

Reilly, G. C., and Engler, A. J. (2010). Intrinsic extracellular matrix properties regulate stem cell differentiation. J. Biomech. 43, 55-62. doi: 10.1016/j.jbiomech.2009.09.009

Robi, K., and Matjaz, V. (2014). Concerns about fibrosis development after scaffolded PRP therapy of muscle injuries: commentary on an article by Sanchez et al.: "Muscle repair: Platelet-rich plasma derivates as a bridge from spontaneity to intervention." Injury 46, 428 doi: 10.1016/j.injury.2014.12.010

Rodriguez-Vita, J., Sanchez-Lopez, E., Esteban, V., Ruperez, M., Egido, J., and Ruiz-Ortega, M. (2005). Angiotensin II activates the Smad pathway in vascular smooth muscle cells by a transforming growth factor-beta-independent mechanism. Circulation 111, 2509-2517. doi: 10.1161/01.CIR.0000165133.84 978.E2

Roffe, S., Hagai, Y., Pines, M., and Halevy, O. (2010). Halofuginone inhibits Smad3 phosphorylation via the PI3K/Akt and MAPK/ERK pathways in muscle cells: effect on myotube fusion. Exp. Cell Res. 316, 1061-1069. doi: 10.1016/j.yexcr.2010.01.003

Rudnicki, M. A., Le Grand, F., McKinnell, I., and Kuang, S. (2008). The molecular regulation of muscle stem cell function. Cold Spring Harb. Symp. Quant. Biol. 73, 323-331. doi: 10.1101/sqb.2008.73.064

Sanchez, M., Anitua, E., Delgado, D., Sanchez, P., Orive, G., and Padilla, S. (2014). Muscle repair: platelet-rich plasma derivates as a bridge from spontaneity to intervention. Injury 45(Suppl. 4), S7-S14. doi: 10.1016/S0020-1383(14)70004-X

Sanes, J. R. (2003). The basement membrane/basal lamina of skeletal muscle. J. Biol. Chem. 278, 12601-12604. doi: 10.1074/jbc.R200027200

Sarrazy, V., Billet, F., Micallef, L., Coulomb, B., and Desmoulière, A. (2011). Mechanisms of pathological scarring: role of myofibroblasts and current developments. Wound Repair Regen. 19, S10-S15. doi: 10.1111/j.1524475X.2011.00708.x

Sato, K., Li, Y., Foster, W., Fukushima, K., Badlani, N., Adachi, N., et al. (2003). Improvement of muscle healing through enhancement of muscle regeneration and prevention of fibrosis. Muscle Nerve 28, 365-372. doi: 10.1002/mus.10436

Serrano, A. L., and Munoz-Canoves, P. (2010). Regulation and dysregulation of fibrosis in skeletal muscle. Exp. Cell Res. 316, 3050-3058. doi: 10.1016/j.yexcr.2010.05.035

Serrano, A. L., Mann, C. J., Vidal, B., Ardite, E., Perdiguero, E., and MunozCanoves, P. (2011). Cellular and molecular mechanisms regulating fibrosis in skeletal muscle repair and disease. Curr. Top Dev. Biol. 96, 167-201. doi: 10.1016/B978-0-12-385940-2.00007-3

Sheppard, D. (2006). Transforming growth factor beta: a central modulator of pulmonary and airway inflammation and fibrosis. Proc. Am. Thorac. Soc. 3, 413-417. doi: 10.1513/pats.200601-008AW

Smith, C., Kruger, M. J., Smith, R. M., and Myburgh, K. H. (2008). The inflammatory response to skeletal muscle injury: illuminating complexities. Sports Med. 38, 947-969. doi: 10.2165/00007256-200838110-00005

Spurney, C. F., Sali, A., Guerron, A. D., Iantorno, M., Yu, Q., Gordish-Dressman, H., et al. (2011). Losartan decreases cardiacmuscle fibrosis and improves car- diac function in dystrophin-deficient $\mathrm{mdx}$ mice. J. Cardiovasc. Pharmacol. Ther. 16, 87-95. doi: 10.1177/1074248410381757

Stauber, W. T., Knack, K. K., Miller, G. R., and Grimmett, J. G. (1996). Fibrosis and intercellular collagen connections from four weeks of muscle strains. Muscle Nerve 19, 423-430. doi: 10.1002/mus.880190402

Street, S. F., and Ramsey, R. W. (1965). Sarcolemma: transmitter of active tension in frog skeletal muscle. Science 149, 1379-1380. doi: 10.1126/science.149.3690.1379

Taniguti, A. P., Pertille, A., Matsumura, C. Y., Santo Neto, H., and Marques, M. J. (2011). Prevention of muscle fibrosis and myonecrosis in $\mathrm{mdx}$ mice by suramin, a TGF-betal blocker. Muscle Nerve 43, 82-87. doi: 10.1002/mus.21869

Terada, S., Ota, S., Kobayashi, M., Kobayashi, T., Mifune, Y., Takayama, K., et al. (2013). Use of an antifibrotic agent improves the effect of platelet-rich plasma on muscle healing after injury. J. Bone Joint Surg. Am. 95, 980-988. doi: 10.2106/JBJS.L.00266

Tidball, J. G. (2005). Inflammatory processes in muscle injury and repair. Am. J. Physiol. Regul. Integr. Comp. Physiol. 288, R345-R353. doi: 10.1152/ajpregu.00454.2004

Tidball, J. G., and Villalta, S. A. (2010). Regulatory interactions between muscle and the immune system during muscle regeneration. Am. J. Physiol. Regul. Integr. Comp. Physiol. 298, R1173-R1187. doi: 10.1152/ajpregu.00735.2009

Tonogai, I., Takahashi, M., Yukata, K., Sato, R., Nikawa, T., Yasui, N., et al. (2014). Osteoactivin attenuates skeletal muscle fibrosis after distraction osteogenesis by promoting extracellular matrix degradation/remodeling. J. Pediatr. Orthop. B 24, 162-169. doi: 10.1097/BPB.0000000000000117

Torrente, Y., El Fahime, E., Caron, N. J., Del Bo, R., Belicchi, M., Pisati, F., et al. (2003). Tumor necrosis factor-alpha (TNF-alpha) stimulates chemotactic response in mouse myogenic cells. Cell Transplant. 12, 91-100. doi: 10.3727/000000003783985115

Tuxhorn, J. A., Ayala, G. E., Smith, M. J., Smith, V. C., Dang, T. D., and Rowley, D. R. (2002). Reactive stroma in human prostate cancer: induction of myofibroblast phenotype and extracellular matrix remodeling. Clin. Cancer Res. 8 , 2912-2923.

Vaday, G. G., Schor, H., Rahat, M. A., Lahat, N., and Lider, O. (2001). Transforming growth factor-beta suppresses tumor necrosis factor alpha-induced matrix metalloproteinase-9 expression in monocytes. J. Leukoc. Biol. 69, 613-621.

Van Erp, C., Irwin, N. G., and Hoey, A. J. (2006). Long-term administration of pirfenidone improves cardiac function in mdx mice. Muscle Nerve 34, 327-334. doi: $10.1002 /$ mus. 20590

Wehling-Henricks, M., Jordan, M. C., Gotoh, T., Grody, W. W., Roos, K. P., and Tidball, J. G. (2010). Arginine metabolism by macrophages promotes cardiac and muscle fibrosis in mdx muscular dystrophy. PLoS ONE 5:e10763. doi: 10.1371/journal.pone.0010763

Wynn, T. A. (2004). Fibrotic disease and the $\mathrm{T}(\mathrm{H}) 1 / \mathrm{T}(\mathrm{H}) 2$ paradigm. Nat. Rev. Immunol. 4, 583-594. doi: 10.1038/nri1412

Wynn, T. A., and Ramalingam, T. R. (2012). Mechanisms of fibrosis: therapeutic translation for fibrotic disease. Nat. Med. 18, 1028-1040. doi: 10.1038/nm.2807

Wynn, T., and Barron, L. (2010). Macrophages: master regulators of inflammation and fibrosis. Semin. Liver Dis. 30, 245-257. doi: 10.1055/s-0030-1255354

Yan, Z., Choi, S., Liu, X., Zhang, M., Schageman, J. J., Lee, S. Y., et al. (2003). Highly coordinated gene regulation in mouse skeletal muscle regeneration. J. Biol. Chem. 278, 8826-8836. doi: 10.1074/jbc.M209879200

Yuan, W., and Varga, J. (2001). Transforming growth factor-beta repression of matrix metalloproteinase-1 in dermal fibroblasts involves Smad3. J. Biol. Chem. 276, 38502-38510. doi: 10.1074/jbc.M107081200

Zambraski, E. J., and Yancosek, K. E. (2012). Prevention and rehabilitation of musculoskeletal injuries during military operations and training. J. Strength Cond. Res. 26(Suppl. 2), S101-S106. doi: 10.1519/JSC.0b013e31825cf03b

Conflict of Interest Statement: The authors declare that the research was conducted in the absence of any commercial or financial relationships that could be construed as a potential conflict of interest.

Copyright (c) 2015 Garg, Corona and Walters. This is an open-access article distributed under the terms of the Creative Commons Attribution License (CC BY). The use, distribution or reproduction in other forums is permitted, provided the original author(s) or licensor are credited and that the original publication in this journal is cited, in accordance with accepted academic practice. No use, distribution or reproduction is permitted which does not comply with these terms. 